\title{
Structural, physicochemical characterization and antimicrobial activities of a new Tetraaqua bismaleato Iron(II) complex
}

\author{
BADIAA ESSGHAIER $^{\mathrm{a}, *}$, JAWHER ABDELHAK $^{\mathrm{b}}$, AMANI NAOUAR $^{\mathrm{a}}$, \\ NOURCHENE TOUKEBRI ${ }^{\mathrm{a}}$, MOHAMED FAOUZI ZID ${ }^{\mathrm{b}}$ and NAJLA SADFI-ZOUAOUI ${ }^{\mathrm{a}}$ \\ ${ }^{a}$ Laboratoire Microorganismes et Biomolécules Actives, Faculté des Sciences, 2092 El Manar, Tunis, Tunisie \\ b Laboratoire de Matériaux et Cristallochimie, Département de chimie, Faculté des Sciences, \\ 2092 El Manar, Tunis, Tunisie \\ e-mail: badiaaessghaier@gmail.com; jawher.abdelhak@ipein.rnu.tn
}

MS received 2 June 2015; revised 3 October 2015; accepted 8 October 2015

\begin{abstract}
Tetraaqua bismaleato iron(II) $\left[\mathrm{Fe}\left(\mathrm{C}_{4} \mathrm{H}_{3} \mathrm{O}_{4}\right)_{2}\left(\mathrm{H}_{2} \mathrm{O}\right)_{4}\right]$, (1) is a new synthetic antimicrobial agent. Thermal analysis shows that the dehydration of the compound occurs in agreement with the structure. The single crystal salt crystallizes in the triclinic space group $P-1$ with $a=5.171(2) \AA, b=7.309$ (3) $\AA, c=9.731$ (3) $\AA, \alpha=109.15(2)^{\circ}, \beta=115.02(2)^{\circ}, \gamma=92.42(1)^{\circ}, V=313.6(3) \AA^{3}$ and $\mathrm{Z}=1$. Three dimensional network is formed by strong intermolecular $\mathrm{O}-\mathrm{H} \ldots \mathrm{O}$ hydrogen bonds. Magnetic susceptibility measurements of $\mathbf{1}$ in the range $2-300 \mathrm{~K}$ exhibited paramagnetic behavior at high temperature. However, at low temperature, the susceptibility data showed weak antiferromagnetic interactions between the local spins. Antimicrobial activity of $\mathbf{1}$ was tested. It showed high response against gram-positive and gram-negative bacteria as well as fungi and the MIC and IC50 values ranged from 8 to $256 \mu \mathrm{g} \cdot \mathrm{mL}^{-1}$ and from 1.38 to $22.19 \mu \mathrm{g} \cdot \mathrm{mL}^{-1}$, respectively.
\end{abstract}

Keywords. Bismaleato complex; iron(II); single crystal; magnetic susceptibility; antibacterial; antifungal activities.

\section{Introduction}

The design and synthesis of complexes of carboxylic acids with transition metals are the most captivating studies in coordination chemistry and material science because of their interesting structures and spectroscopic, luminescence, catalytic, magnetic properties. ${ }^{1-3}$ Metal complexes with maleate ligands have been recently investigated. They can form 1D, 2D or 3D networks and polynuclear complexes owing to the ligand coordination via $\mathrm{O}$ atoms and due to the formation of hydrogen bonds. ${ }^{4}$

This work is an extension of previous reports focused on frequently studied structures, $\mathrm{M}^{\mathrm{II}}\left(\mathrm{C}_{4} \mathrm{H}_{3} \mathrm{O}_{4}\right)_{2} \cdot 4 \mathrm{H}_{2} \mathrm{O}$, where $\mathrm{M}$ is $\mathrm{Ni}, \mathrm{Mn}, \mathrm{Cd}$ and $\mathrm{Ba}^{5,6}$ The purpose of the synthesis was to determine the metal ions effect on the coordination of maleato ion on the network of hydrogen bonds and the structural stability of these compounds. In this sense, our investigation has focused on the synthesis and characterization of a new species of the formula $\left[\mathrm{Fe}\left(\mathrm{C}_{4} \mathrm{H}_{3} \mathrm{O}_{4}\right)_{2}\left(\mathrm{H}_{2} \mathrm{O}\right)_{4}\right]$.

The need for new antimicrobial agents is greater than ever because of the emergence of multidrug resistance in common pathogens, the rapid emergence of

*For correspondence new infections, and the potential for use of multidrugresistant agents. ${ }^{7}$ Thus, there is a crucial requirement for the development of new classes of antimicrobial agents and the identification of new drug targets. ${ }^{8} \mathrm{Sev}-$ eral new approaches are required to combat emerging infections and the global spread of drug-resistant pathogens. These trends have emphasized the urgent need for new, more effective, less toxic and safe antimicrobial agents and the development of structurally new classes of antimicrobials with novel mechanisms of action to improve both their binding affinity and their spectrum of activity. Herein, we report the synthesis of a new antimicrobial agent designed tetraaqua bismaleato iron(II) and biological activities.

\section{Experimental}

\subsection{Materials and methods}

All chemicals were commercially purchased and used without further purification. TG/DTA 92 SETARAM thermal analyzer was employed for the investigation of the thermal behavior in $\mathrm{Ar}$ atmosphere from room temperature to $600^{\circ} \mathrm{C}$. UV-Vis spectrum was recorded on a Perkin Elmer UV/Vis spectrometer Lambda 20 
in the range 300-750 $\mathrm{nm}$. Magnetic susceptibility measurements of a polycrystalline sample were carried out using a Quantum design (superconducting quantum interference device SQUID) magnetometer in the temperature range $2-300 \mathrm{~K}$ at a magnetic field of 200 G. The susceptibility data were corrected for diamagnetism estimated from Pascal's tables. ${ }^{9}$

Gram-negative bacterial strains of Pseudomonas aeruginosa, Escherichia coli DH5 $\alpha$ Acinetobacer spp, Agrobacteium tumefaciens and Erwinia spp, grampositive bacterial strains of Listeria innocua, Staphylococcus aureus, three yeasts (Candida albicans) and three fungal strains of dermatophyte(Trichophyton rubrum) were used in the present work. TSB and TSA media were employed throughout the experiments with bacteria. Yeast malt extract broth (YMB) and agar (YMA) were used in the test with Candida albicans and Potato Dextrose Agar (PDA) was used for experiments with fungi.

\subsection{Synthesis}

The title compound, tetraaqua bismaleato iron(II) (1) was prepared as good quality yellow single crystals from a mixture of iron(II) nitrate nanohydrate $(0.3 \mathrm{~g})$, maleic acid $(0.4 \mathrm{~g})$ and phosphoric acid $(3 \mathrm{~mL})$ dissolved in water $(20 \mathrm{~mL})$. The resulting mixture was heated to boiling point and stirred for two hours. Immediately a brown precipitate was formed. After a few days, single crystals were obtained by slow evaporation of an aqueous solution at room temperature. Anal. Found: C,16.02; H,1.73; Fe,12.25; O,24.54\%; Calc. for $\mathrm{C}_{4} \mathrm{H}_{11} \mathrm{FeO}_{8}$ (M.W. 363.09): C,16.3; H,1.62; Fe,12.1; $\mathrm{O}, 25.31 \%$.

\subsection{Crystal structure determination and refinements}

A prismatic red crystal $\left(0.22 \times 0.21 \times 0.13 \mathrm{~mm}^{3}\right)$ was selected for the structural analysis. Diffraction data were collected at 293(2) K with Enraf-Nonius CAD4 automatic four-circle, equipped with a graphite monochromator using $\operatorname{Mo~}_{\alpha}(\lambda=0.71073 \AA)$ radiation with the $\mathrm{w}-2 \theta$ technique. Unit cell parameters and orientation matrix of the crystal were determined by least squares treatment of the setting angles of 25 reflections on the range $10^{\circ}<\theta<15^{\circ}$. The structure was solved by standard Patterson methods and refined by the full-matrix least-squares method on $\mathrm{F}^{2}$ for 287 refined parameters. The structure was solved by direct methods and refined in a full-matrix anisotropic (isotropic for $\mathrm{H}$ ) approximation using the SHELX-97 programs. The $\mathrm{H}$ atoms were located from difference Fourier syntheses

Table 1. Crystallographic and experimental data.

Formula

Formula weight $\left(\mathrm{g} \cdot \mathrm{mol}^{-1}\right)$

Crystal system

Space group

a $(\AA)$

b $(\AA)$

c $(\AA)$

$\alpha\left(^{\circ}\right)$

$\beta\left(^{\circ}\right)$

$\gamma\left({ }^{\circ}\right)$

Volume $\left(\AA^{3}\right)$

Z

$\rho\left(\mathrm{g} . \mathrm{cm}^{-3}\right)$

$\mu\left(\mathrm{mm}^{-1}\right)$

Index ranges

Total data collected

Independent reflections

Reflections with $\mathrm{I}>2 \sigma$ (I)

$\mathrm{R}_{\text {int }}$

Goodness-of-fit on $\mathrm{F}^{2}$

$\mathrm{R}[\mathrm{I}>2 \sigma(\mathrm{I})]^{\mathrm{a}}$

$\mathrm{R}_{\mathrm{W}}[\mathrm{I}>2 \sigma(\mathrm{I})]^{\mathrm{b}}$

Largest difference peak

and hole $\left(\mathrm{e} \AA^{-3}\right)$

${ }^{\mathrm{a}} \mathrm{R}=\Sigma|| \mathrm{F}_{0}|-| \mathrm{F}_{\mathrm{c}}|| / \Sigma\left|\mathrm{F}_{0}\right|$.

${ }^{\mathrm{b}} \mathrm{R}_{\mathrm{w}}=\left[\Sigma \mathrm{w}\left(\left|\mathrm{F}_{0}\right|^{2}\left|-\mathrm{F}_{\mathrm{c}}\right|^{2}\right)^{2} / \Sigma \mathrm{w}\left|\mathrm{F}_{0}\right|^{2}\right]^{1 / 2}$

and refined as a rigid group. Further details of X-ray structural analysis are given in table 1 .

\subsection{Agar diffusion method}

The in vitro antimicrobial test is based on the diffusion method on agar plates as previously reported. ${ }^{10,11}$ Before use, 1 was diluted in distilled water, sterilized by filtration through a $0.2 \mu \mathrm{m}$ pore size filter and adjusted to the appropriate concentration tested. A $50 \mu \mathrm{L}$ aliquot of filtered compound was placed on paper discs. After overnight pre-diffusion at $4^{\circ} \mathrm{C}$, the plates were incubated at appropriate temperature $37^{\circ} \mathrm{C}$ or $30^{\circ} \mathrm{C}$ for at least $24 \mathrm{~h}$ and diameters of inhibition zones were measured in $\mathrm{mm}$.

\subsection{Antifungal activity}

2.5a On PDA plates: $50 \mu \mathrm{L}$ of $\mathbf{1}$ at 200,500 or 1000 $\mu \mathrm{g} \cdot \mathrm{mL}^{-1}$ were used to determine their efficiency on the growth dermatophyte inhibition by applying a dual culture technique as previously detailed. ${ }^{11}$

2.5b In broth cultures of Candida albicans: $100 \mu \mathrm{L}$ of 1 at $200 \mu \mathrm{g} \cdot \mathrm{mL}^{-1}$ was added to $900 \mu \mathrm{L}$ of $\mathrm{YM}$ 
medium containing $10^{5} \mathrm{CFU}$ of yeasts. The culture was then grown at $37^{\circ} \mathrm{C}$ on a shaker for $48 \mathrm{~h}$, as previously detailed. $^{12}$

\subsection{Determination of MIC and IC50}

The MIC ( $\mu$ g. $\left.\mathrm{mL}^{-1}\right)$ was taken as the lowest concentration (highest dilution) without visible growth, and IC50 $\left(\mu \mathrm{g} . \mathrm{mL}^{-1}\right)$ is the concentration at which $50 \%$ inhibition of the response is seen. MIC and IC50 value were evaluated by using the serial double dilution method in the appropriate medium which is inoculated with a standardized number of microorganisms. The concentration of $\mathbf{1}$ incubated with indicator strain is given in $\mu \mathrm{g} \cdot \mathrm{mL}^{-1}$. Each dilution of 1 affected in $1000 \mu \mathrm{L}$ of the appropriate medium was inoculated by $100 \mu \mathrm{L}$ of $10^{6} \mathrm{CFU}$ $\mathrm{mL}^{-1}$ of each indicator strain then the different culture tubes were incubated at appropriate temperature. Control tube containing $100 \mu \mathrm{L}$ of $10^{6} \mathrm{CFU} . \mathrm{mL}^{-1}$ of each indicator strain, added to $1000 \mu \mathrm{L}$ of culture medium without 1. MIC was estimated visually (absence of turbidity) and were determined with 3 independent measurements. ${ }^{13}$

\subsection{Determination of bactericide activity}

The antimicrobial activity of solutions of $\mathbf{1}$ was expressed in arbitrary units per $\mathrm{mL}\left(\mathrm{AU} \cdot \mathrm{mL}^{-1}\right)$ and it was determined by an agar diffusion assay as previously described. ${ }^{14}$ Briefly, a serial two-fold dilution in sterile distilled water of 1 was prepared, and $50 \mu \mathrm{L}$ of each dilution were spotted onto a TSB agar soft plate seeded with about $10^{5} \mathrm{CFU} . \mathrm{mL}^{-1}$ of Staphylococcus aureus. The AU/mL was calculated as: $\mathrm{AU} / \mathrm{mL}=1000 \mathrm{X} \mathrm{D} / \mathrm{A}$, where $\mathrm{A}$ is the volume of the $\mathbf{1}$ aliquot spotted on agar plate (50 $\mu \mathrm{L}$ in this case), D is the reciprocal of the highest dilution showing a clear inhibition of the indicator strain.

\subsection{Lysozyme activity}

The Lysozyme activity of the $\mathbf{1}$ was assayed turbidimetrically by measuring the decrease in absorbance at 660 $\mathrm{nm}$ of a suspension of Staphylococcus. aureus. ${ }^{14}$

\subsection{Mycelial hyphae destruction}

Fungal culture was rinsed with distilled sterile water. After centrifugation at $9000 \mathrm{rpm}$ for $10 \mathrm{~min}$ pellet (mycelium) was replaced in an Eppendorf tube containing an appropriate Tris-HCl buffer $(0,01 \mathrm{M}, \mathrm{pH} 8)$ in order to obtain the same concentration of mycelial solution (expressed in mg.mL ${ }^{-1}$ ). $200 \mu \mathrm{L}$ of $1000 \mu \mathrm{g} \cdot \mathrm{mL}^{-1}$ of the title compound was added. The mixture was incubated at $37^{\circ} \mathrm{C}$ for $14 \mathrm{~h}$. Optical density was measured at $540 \mathrm{~nm}$. Increase of OD was compared to control tube (containing only mycelial suspension) to make destruction of fungal hyphae by the compound. ${ }^{15}$

\section{Results and Discussion}

\subsection{Crystal structure description}

The title compound crystallized in the triclinic space group $P-1$. The $\mathrm{Fe}$ cations occupy inversion centers and the monodentate hydrogen maleate $\left[\mathrm{C}_{4} \mathrm{H}_{3} \mathrm{O}_{4}\right]^{-}$ligands are in a trans configuration (figure 1). The distorted octahedral iron coordination is completed by four water molecules, with $\mathrm{Fe}-\mathrm{O}$ distances between 2.028(1) and 2.141(1) $\AA$. The equatorial plane of the octahedron is formed by four oxygen atoms of water molecules $(\mathrm{O} 2$, $\left.\mathrm{O} 2^{\mathrm{i}}\right)$ and anions maleato $\left(\mathrm{O} 3\right.$ and $\left.\mathrm{O}^{\mathrm{i}}\right)$ for the equation: $0,012(2) \mathrm{x}-2,881$ (3) $\mathrm{y}+4,487$ (4) $\mathrm{z}=5,441$.

The elongation observed for $\mathrm{M}-\mathrm{O} 2$ and $\mathrm{M}-\mathrm{O} 3$ bonds with respect to M-O1 is probably due to the steric hindrance caused by the maleato groups which are quite bulky. Thereby, the maleato ion acts as a monodentate ligand bound by single oxygen. A maleic acid has a mirror-like symmetry perpendicular to the $\mathrm{C} 2-\mathrm{C} 3$ (table 2).

The distance $\mathrm{C}-\mathrm{C}$ is between 1.23(3) $\AA$ and 1.32(3) $\AA$, whereas the carbon - oxygen distance are of two types. The first category concerns the free oxygen atoms, where the distance $\mathrm{C}-\mathrm{O}_{\text {free }}$ is between 1.26(2) $\AA$ and

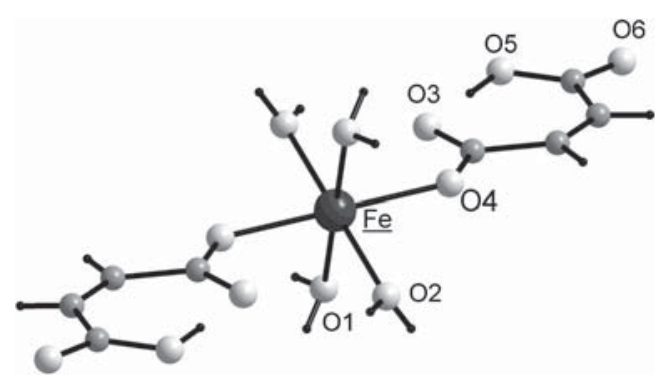

Figure 1. Molecular structure of $\left[\mathrm{Fe}\left(\mathrm{C}_{4} \mathrm{H}_{3} \mathrm{O}_{4}\right)_{2}\left(\mathrm{H}_{2} \mathrm{O}\right)_{4}\right]$.

Table 2. Selected bond lengths $(\AA)$ and angles $\left(^{\circ}\right)$ in the octahedron $\mathrm{FeO}_{6}$.

\begin{tabular}{llcc}
\hline $\mathbf{F e}-\mathrm{O} 1$ & $2.028(1)$ & $\mathrm{O} 1-\mathbf{F e}-\mathrm{O} 2$ & $92.31(5)$ \\
$\mathbf{F e}-\mathrm{O} 2$ & $2.117(1)$ & $\mathrm{O} 1-\mathbf{F e}-\mathrm{O} 3$ & $84.31(1)$ \\
$\mathbf{F e}-\mathrm{O} 3$ & $2.141(1)$ & $\mathrm{O} 2-\mathbf{F e}-\mathrm{O} 3$ & $90.55(5)$ \\
& & $\mathrm{O} 1-\mathbf{F e}-\mathrm{O} 1^{\mathrm{i}}$ & $180.19(5)$ \\
& & $\mathrm{O} 2-\mathbf{F e}-\mathrm{O} 2^{\mathrm{i}}$ & $179.08(5)$ \\
& & $\mathrm{O} 3-\mathbf{F e}-3^{\mathrm{i}}$ & $180.00(4)$ \\
\hline
\end{tabular}

Symmetry Code $\boldsymbol{i}:-\mathrm{x},-\mathrm{y},-\mathrm{z}$. 


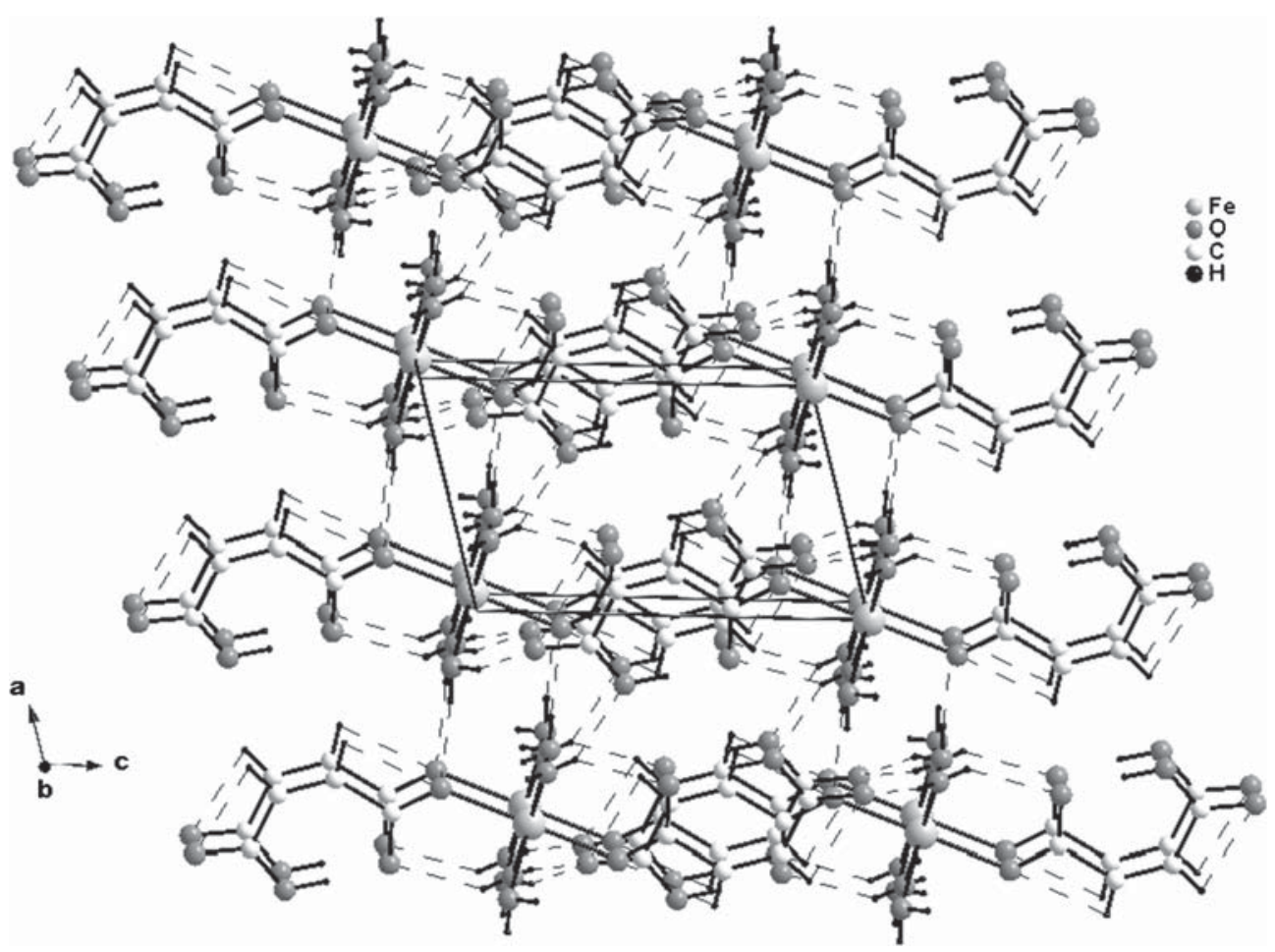

Figure 2. Fragments of the molecular structure showing directional hydrogen bonding interactions.

Table 3. Selected hydrogen-bond parameters for $\left[\mathrm{Fe}\left(\mathrm{C}_{4}\right.\right.$ $\left.\left.\mathrm{H}_{3} \mathrm{O}_{4}\right)_{2}\left(\mathrm{H}_{2} \mathrm{O}\right)_{4}\right]$

\begin{tabular}{lcccccc}
\hline $\mathrm{D}$ & $\mathrm{H}$ & $\mathrm{A}$ & $\mathrm{D}-\mathrm{H}(\AA)$ & $\mathrm{H} . . . \mathrm{A}(\AA)$ & $\mathrm{D} . . \mathrm{A}(\AA)$ & $\mathrm{D}-\mathrm{H} . . \mathrm{A}\left({ }^{\circ}\right)$ \\
\hline $\mathrm{O} 2$ & $\mathrm{H} 4$ & $\mathrm{O}^{\mathrm{ii}}$ & $0.68(3)$ & $2.13(4)$ & $2.811(2)$ & $178(4)$ \\
$\mathrm{O} 2$ & $\mathrm{H} 3$ & $\mathrm{O} 6$ & $0.82(3)$ & $1.91(3)$ & $2.725(2)$ & $178(3)$ \\
$\mathrm{O} 4$ & $\mathrm{H} 5$ & $\mathrm{O3}^{\mathrm{iii}}$ & $0.86(5)$ & $1.93(5)$ & $2.777(2)$ & $170(3)$
\end{tabular}

D: donor; A: acceptor.

Codes of symmetry $\boldsymbol{i i}:-\mathrm{x},-\mathrm{y},-\mathrm{z}+1$; iii: $\mathrm{x},-\mathrm{y}+1, \mathrm{z}-1$.

1.29(3) $\AA$, for the second category, oxygen atoms bound to metal ions, $\mathrm{d}\left(\mathrm{C}-\mathrm{O}_{\text {linked }}\right)=1.23(4) \AA$. These values are of the same order of magnitude as those reported. ${ }^{16}$

In the crystal structure, the molecules are packed via hydrogen bonds (figure 2) between water molecules and the uncoordinated $\mathrm{O}$ (maleate) atoms of neighboring molecules forming a two dimensional supramolecular structure (table 3 ).

\subsection{IR Spectra}

The infrared spectrum of compound $\left[\mathrm{Fe}\left(\mathrm{C}_{4} \mathrm{H}_{3} \mathrm{O}_{4}\right)_{2}\right.$ $\left(\mathrm{H}_{2} \mathrm{O}\right)_{4}$ ] shows peaks relating to the maleate group. Asymmetric vibration modes of the CO bridge appear at $1630 \mathrm{~cm}^{-1}$. The peak at 1365 may also be attributed to the symmetric vibration of $\mathrm{C}=\mathrm{O}$, so that the peaks in the vicinity of $750 \mathrm{~cm}^{-1}$ are assigned to the deformation vibration $\delta(\mathrm{OCO})$. The broad absorption band bet- ween $3500-2900 \mathrm{~cm}^{-1}$ can be attributed to $\mathrm{OH}$ and $\mathrm{CH}$ stretching vibrations. While peaks between 1250-600 $\mathrm{cm}^{-1}$ correspond to the carboxylic group deformations and $\delta(\mathrm{OH})$ vibrations. The peak at around $504 \mathrm{~cm}^{-1}$ is attributed to the stretching vibration $v(\mathrm{Fe}-\mathrm{O})$. These allocations are in line with previous results. ${ }^{17}$

\subsection{Thermal analysis}

Thermal analysis was performed under a nitrogen atmosphere with a heating rate of $5^{\circ} \mathrm{C} \cdot \mathrm{min}^{-1}$ in a range between room temperature and $600^{\circ} \mathrm{C}$. The TGA curve shows a mass loss corresponding to four water molecules (dehydration), this loss is reflected in the DTA curve with an endothermic peak at $177^{\circ} \mathrm{C}$. In fact, the dehydration of the compound is in agreement with the structural study where we found that the cohesion between layers is ensured by strong hydrogen bonds between the water molecules and the maleate group of oxygen atoms. The percentage of the first loss of the mass is $22.72 \%$, which is in agreement with the theoretical loss of four water molecules, $20.94 \%$. From $350^{\circ} \mathrm{C}$, there is the decomposition of the organic group.

\subsection{Electronic Spectra}

Electronic absorption spectrum was obtained in ethanol solution. The absorption spectrum of the complex 
shows very intense bands in the UV. For a $\mathrm{Fe}^{2+}$ ion with a d $\mathrm{d}^{6}$ configuration in an $\mathrm{O}_{\mathrm{h}}$ crystal field and assuming a low-spin electronic configuration of complex, the ${ }^{1} \mathrm{~A}_{1 \mathrm{~g}}$ term is the ground state. Two lower energy transitions, ${ }^{1} \mathrm{~A}_{1 \mathrm{~g}} \rightarrow{ }^{1} \mathrm{~T}_{1 \mathrm{~g}}$ and ${ }^{1} \mathrm{~A}_{1 \mathrm{~g}} \rightarrow{ }^{1} \mathrm{~T}_{2 \mathrm{~g}}$ exhibit symmetryand spin-forbidden character. ${ }^{18,19}$ The peaks at $642 \mathrm{~nm}$ and $411 \mathrm{~nm}$ correspond to the two $\mathrm{t}_{2 \mathrm{~g}} \rightarrow \mathrm{e}_{\mathrm{g}}$ transitions. These represent, respectively, the ${ }^{1} \mathrm{~A}_{1 \mathrm{~g}} \rightarrow{ }^{1} \mathrm{~T}_{1 \mathrm{~g}}$ and ${ }^{1} \mathrm{~A}_{1 \mathrm{~g}} \rightarrow{ }^{1} \mathrm{~T}_{2 \mathrm{~g}}$ transitions.

\subsection{Magnetic Measurements}

The magnetic susceptibility data for polycrystalline samples of 1 were collected in the 2-300 K range, and the thermal variations of $\chi_{\mathrm{m}}$ and $\chi_{\mathrm{m}}^{-1}$ are shown in figure 3. It can be clearly seen that the sample is in a paramagnetic above $44 \mathrm{~K}$. The plot of $\chi_{\mathrm{m}}^{-1}$ versus temperature shows an exact linear relation at high temperature, which is well fitted by the Curie-Weiss equation, $\chi=\mathrm{C} /(\mathrm{T}-\theta)$, where $\mathrm{C}$ and $\theta$ are the Curie-Weiss constant and magnetic coupling parameter, respectively, to yield values for $\mathrm{C}$ and $\theta$ as, $3.37 \mathrm{~cm}^{3} . \mathrm{K}^{\mathrm{m}} \mathrm{mol}^{-1}$ and -1.88 $\mathrm{K}$ respectively. The highly negative $\theta$ value indicates dominant antiferromagnetic interactions.

An effective moment by formula unit can be extracted using the formula $\left(\frac{\mu_{e f f}}{\mu_{B}}\right)^{2}=\frac{3 K_{B} C}{N}$.

Here, $\mathrm{k}_{\mathrm{B}}$ is Boltzmann constant, $\mathrm{C}$, Curie constant, $N$, the Avogadro's number, and $\mu_{B}$, Bohr magneton. In the spin-only picture usually followed for localized spins of $3 \mathrm{~d}$ ions, $\mu_{\text {eff }}$ is given by:

$\mu_{\text {eff }}=g[S(S+1)]^{1 / 2} \mu_{B}$, where $\mathrm{g}=2.0$ and $\mathrm{S}=$ 2 as usually observed for high-spin iron(II) complexes. The experimental value of $\mu_{\text {eff }}$ is higher than the theoretical spin-only value for $\mathrm{Fe}^{2+}\left(\frac{\mu_{e f f}}{\mu_{B}}=\sqrt{24}=4.90\right)$.

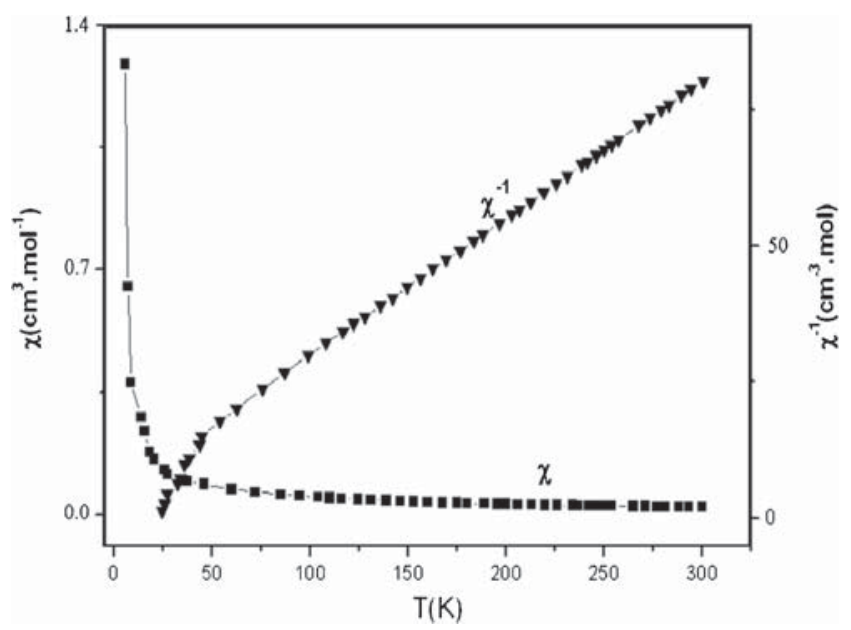

Figure 3. Thermal dependence of $\chi_{m}(\boldsymbol{\square})$ and $\chi_{\mathrm{m}}^{-1}(\boldsymbol{\nabla})$ for compound (1).
At room-temperature the magnetic moment of the compound is $\chi_{\mathrm{m}} \mathrm{T}=3.59 \mathrm{~cm}^{3} \mathrm{~mol}^{-1} . \mathrm{K}$, typical for HS iron(II). When the temperature decreases, the product value $\chi_{\mathrm{m}} \mathrm{T}$ gradually decreases until $2.36 \mathrm{~cm}^{3} \mathrm{~mol}^{-1}$ $\mathrm{K}$. The local anisotropy of the metal ions (zero-field splitting effects) and/or intermolecular antiferromagnetic interactions of iron-iron would account for the observed decrease of $\chi_{\mathrm{m}} \mathrm{T}$ in the very low temperature domain causing the deviation from the Curie law. ${ }^{20}$ To distinguish between these possibilities, we modeled the experimental data using a model that takes account of the ZFS parameter D in the equation of the molar magnetic susceptibility. ${ }^{21}$

$$
\begin{gathered}
\chi_{m}=\frac{N g^{2} \mu_{\beta}^{2}}{3 k_{B} T}\left(\chi_{\|}+2 \chi_{\perp}\right) \text { with } \chi_{\|}=\frac{1+9 e^{\frac{-2 D}{k_{B} T}}}{4\left(1+e^{\frac{-2 D}{k_{B} T}}\right)} \\
\text { and } \chi_{\perp}=\frac{4+\left(\frac{3 k_{B} T}{D}\right)\left(1+9 e^{\frac{-2 D}{k_{B} T}}\right)}{4\left(1+e^{\frac{-2 D}{k_{B} T}}\right)}
\end{gathered}
$$

Thus, it is concluded that the decrease was mainly due to $\chi_{\mathrm{m}} \mathrm{T}$ antiferromagnetic interactions that take place between the magnetic centers with very low or no contribution to ZFS. Therefore, based on these results, we can say that the field exerted by the ligands is weak (strong spin: HS). The refinement leads to a good agreement with the experimental $\chi_{\mathrm{m}} \mathrm{T}$ product for $\mathrm{D}=$ $6.10^{-3} \mathrm{~cm}^{-1}$ and TIP $=13.10^{-4} \mathrm{~cm}^{3} \cdot \mathrm{mol}^{-1}$. This conclusion agrees well with the results of the X-ray structure determination showing that the shortest $\mathrm{Fe}-\mathrm{Fe}$ distance exceeds $5 \AA$. It also suggests the absence of bridging ligands in this complex.

\subsection{Antimicrobial activity}

New antimicrobial agents are always needed to counteract the resistant pathogens that continue to be selected by current therapeutic regimens. In this context comes the objective of the present work to evaluate the antimicrobial potentialities of a new synthesized compound, tetraaqua bismaleato iron(II).

The antibacterial activities of the compound used at $100 \mu \mathrm{g} \cdot \mathrm{mL}^{-1}$, varied with the tested microorganisms; high activities were observed against Pseudomonas aeruginosa, Escherchia coli and Acinetobacter spp with a diameter of inhibition of, respectively, 15.5, 15 and $12 \mathrm{~mm}$. Antifungal activity was also observed by $\mathbf{1}$ at $500 \mu \mathrm{g} \cdot \mathrm{mL}^{-1}$ against species of Candida albicans with diameter inhibition of $14 \mathrm{~mm}$. Noteworthy, that 
1 was unable to inhibit fungi growth of the dermatophyte species used in this work by means of dual culture technique at the same concentration of $100 \mu \mathrm{g} \cdot \mathrm{mL}^{-1}$, neither by the application of 500 or $1000 \mu \mathrm{g} \cdot \mathrm{mL}^{-1}$.

On the whole, the results showed that 1 possesses high antibacterial activity at $100 \mu \mathrm{g} \cdot \mathrm{mL}^{-1}$ compared to other published synthetic compounds. ${ }^{22}$ At the highest concentration of about $500 \mu \mathrm{g} \cdot \mathrm{mL}^{-1}$ of 1 also activity against Candida albicans strains has been obtained, similar to results obtained by synthetic compound reported. ${ }^{22}$

For antifungal activities numerous compounds had shown activity when applied with a concentration greater than $500 \mu \mathrm{g} . \mathrm{mL}^{-1}$. In the present work, at $1000 \mu \mathrm{g} . \mathrm{mL}^{-1}$, we have no antifungal activities in solid media compared to the antifungal activity exhibited by other synthetic compound. ${ }^{22,23}$ For example, a number of methyl imidazole derivatives and some of their oxygenated products tested ${ }^{23}$ were found to exert very low antifungal activity against yeasts and moulds. ${ }^{23}$ The success of the application of Histidine-lysine (HK) polymers against the growth of several species of Candida albicans was described. ${ }^{12}$

In the light of the recently reported data, we decided to analyze the mechanism of action of the compound. For that, we have investigated the antifungal activities in broth medium for yeast and fungi. The results of the antifungal effect of $\mathbf{1}$ investigated in broth cultures of Candida albicans was determined as percent of yeast survival by measuring optical density at $600 \mathrm{~nm}$. The obtained results showed that the application of $\mathbf{1}$ only at $200 \mu \mathrm{g} \cdot \mathrm{mL}^{-1}$ was able to successfully suppress yeast survival by value ranging from 40.5 to $76.81 \mathrm{AU}$ with various yeast strains tested in the present work, after incubation at $37^{\circ} \mathrm{C}$ for $48 \mathrm{~h}$ (figure 4).

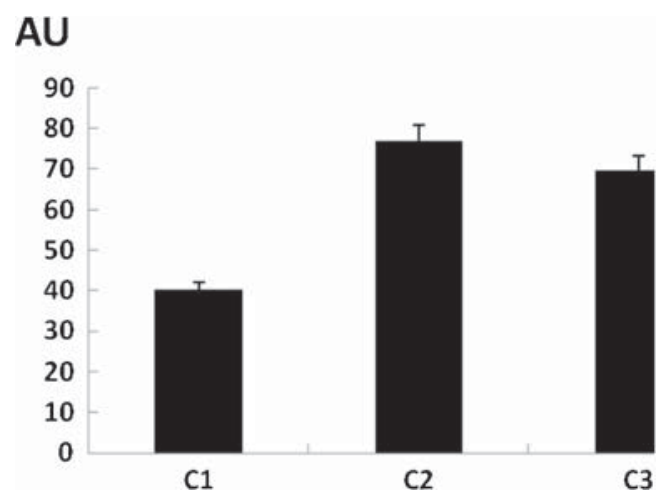

Figure 4. The effect of $\mathbf{1}$ at $200 \mu \mathrm{g} \cdot \mathrm{mL}^{-1}$ on three strains of Candida albicans, C1, C2 and C3, tested by incubation for $14 \mathrm{~h}$ at $37^{\circ} \mathrm{C}$. AU was expressed by comparison with untreated yeast suspension (incubation tube without 1). Data are the average of three replications \pm the standard error of the mean.
Previously, we have shown that the sulfanilamide sulphate used at $100 \mu \mathrm{g} . \mathrm{mL}^{-1}$ was able to suppress yeast survival only with $55.77 \mathrm{AU}^{11}$ and the aminochloropyridinium diaqua dioxalato iron(III) with value ranging from 45.45 to $24.53 \mathrm{AU}^{24}$ These results show markedly high anti-Candida activities of the new compound described here with value $76.81 \mathrm{AU}$ and 69.64 AU.

The values of MIC and IC50 are presented in table 4. The results have shown that MIC ranged from $8 \mu \mathrm{g} \cdot \mathrm{mL}^{-1}$ for bacteria to $256 \mu \mathrm{g} \cdot \mathrm{mL}^{-1}$ for yeast and IC50 values varying from 1.38 to $1.59 \mu \mathrm{g} \cdot \mathrm{mL}^{-1}$ for bacteria and 22.19 for yeast. These results show that $\mathbf{1}$ had especially high activity against bacteria compared to yeast and fungi. Similar results of the promising antibacterial activities have been reported by two compounds ${ }^{25}$ against $B$. subtilis with MIC of 1.12, $3.66 \mu \mathrm{g} \cdot \mathrm{mL}^{-1}$.

Our compound $\mathbf{1}$ has high antibacterial activities compared to a series of simple heterocyclic chalcone analogues described earlier, ${ }^{26}$ which has moderate antibacterial activities since MIC exceed $32 \mu \mathrm{g} \cdot \mathrm{mL}^{-1}{ }^{26}$ Because of high antibacterial activities exhibited 1, in the same context, we would evaluate their lysozyme and the bactericidal activities. The bactericide activity of $\mathbf{1}$ was expressed in arbitrary units per $\mathrm{mL}^{-1}\left(\right.$ AU.mL $\left.{ }^{-1}\right)$. The obtained results have shown that $\mathbf{1}$ had a high bactericidal activity of about 2500 AU.mL ${ }^{-1}$. It should be mentioned that this value is greater than that exhibited by our previous compound di(4-sulfamoyl-phenylammonium) sulphate. ${ }^{11}$

High lysozyme activities were expressed against Listeria innocua with $0.95 \mathrm{AU}$, greater than Staphytococcus aureus 0.087 AU. Lysozyme activities were directed toward membranes of gram-positive bacteria that are essentially constituted of peptidoglycans. Previously, similar high lysozyme activity against Listeria innocua was exhibited by other synthetic compounds as reported by our laboratory. ${ }^{24}$

The direct effect of the compound on mycelia growth gives an idea of the ability of the compound to

Table 4. MIC $\left(\mu \mathrm{g} \cdot \mathrm{mL}^{-1}\right)$ and IC50 values $\left(\mu \mathrm{g} \cdot \mathrm{mL}^{-1}\right)$ of Tetraaqua bismaleatofer(II) against pathogenic bacteria and yeast.

\begin{tabular}{lcc}
\hline Microorganisms & $\begin{array}{c}\mathrm{MIC} \\
\text { (in } \mu \mathrm{g} \cdot \mathrm{mL}^{-1} \text { ) }\end{array}$ & $\begin{array}{c}\mathrm{IC50} \\
\text { (in } \mu \mathrm{g} \cdot \mathrm{mL}^{-1} \text { ) }\end{array}$ \\
\hline $\begin{array}{l}\text { Bacteria } \\
\text { Escherichia coli }\end{array}$ & 8 & 1.38 \\
$\begin{array}{l}\text { Pseudomonas } \\
\text { aeruginosa }\end{array}$ & 8 & 1.59 \\
$\begin{array}{l}\text { Acinetobacter } \\
\text { Yeast }\end{array}$ & 8 & 1.5 \\
Candida albicans & 256 & 22.19 \\
\hline
\end{tabular}


physically destruct the fungal hyphe. Markedly, the results of the investigation of the present compound showed that it was able to destruct the hyphe mycelial of three strains of the dermatophyte Trichophyton rubrum $\mathrm{T} 1, \mathrm{~T} 2$ and $\mathrm{T} 3$ with values ranging from 0.057 to 0.632 AU. However, the high antifungal activities were obtained against T2 strain with $57 \%$ more than that for the strain T3 with 38\%. The effect of $\mathbf{1}$ was markedly distinguished by the microscopic observation compared to untreated mycelium characterized by long hyphe (figure 5). It should be noted that $\mathbf{1}$ has high antifungal activities than our previous compound with activity not exceeding 0.1 AU against three tested dermatophyte strains. $^{24}$

In previous work, we had shown the ability of di(4sulfamoyl-phenyl-ammonium) sulphate to inhibit some phytopathogenic fungi by affecting the spores germination and mycelia fragmentation of fungi, ${ }^{11}$ which could be useful in agriculture purposes. In this paper, the title compound was able to inhibit three strains of dermatophyte as well as three strains of Candida albicans. Based on the interest in antimicrobial activities, this new compound described here can be a promising antimicrobial agent.
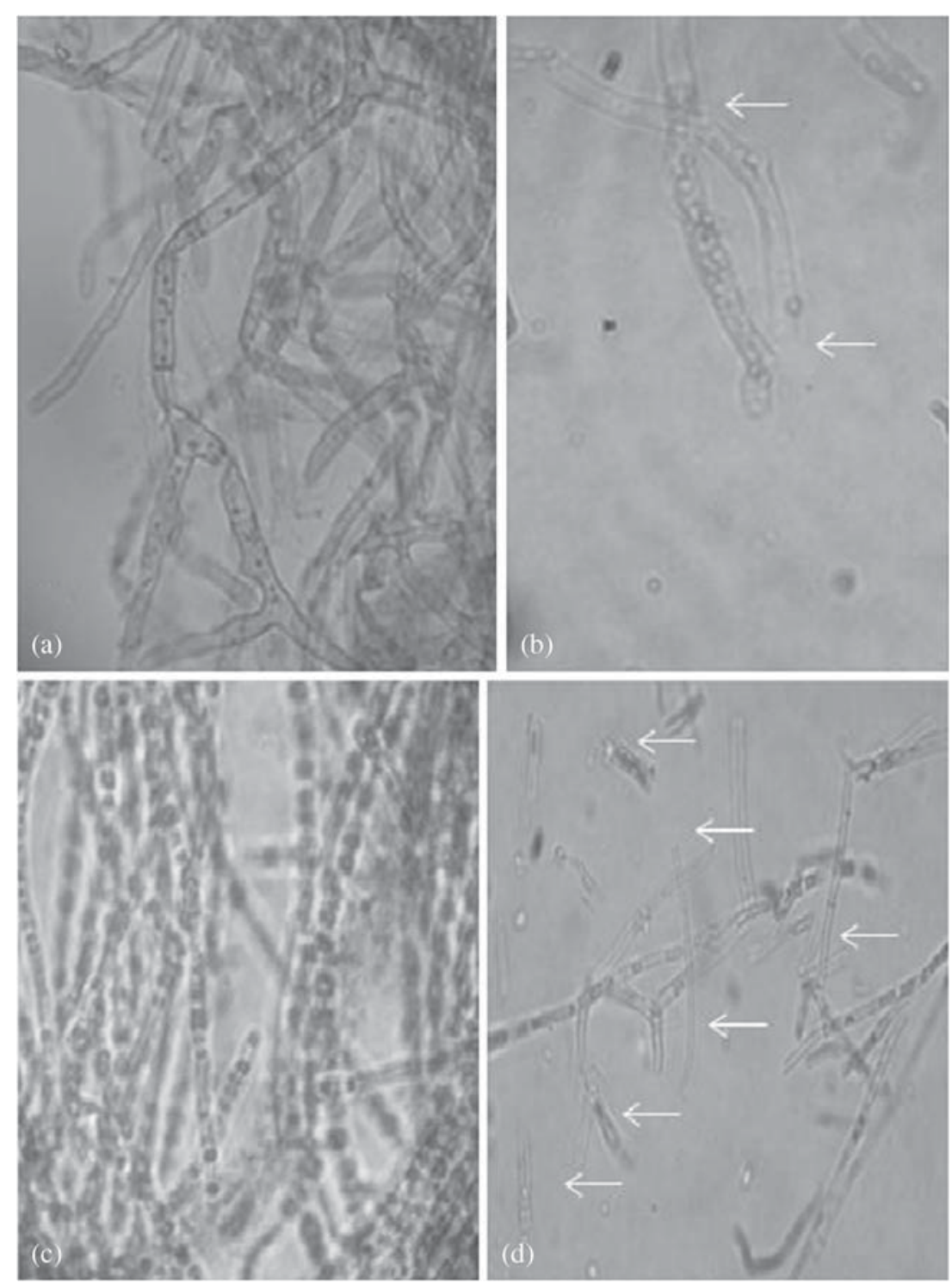

Figure 5. Microscopic observation of the effect of tetraaqua bismaleato iron(II) at $1000 \mu \mathrm{g} \cdot \mathrm{mL}^{-1}$ on mycelial fragmentation of two strains $\mathrm{T} 2$ and T3 of Trichophyton rubrum (b) and (d), respectively; compared to untreated mycelial suspension (incubation tube without 1, (a) and (c), respectively. Arrow indicates area of fragmentation and destruction hyphea compared to long hyphea in the normal case without treatment. Optical microscopic observation at 40X magnification. 


\section{Conclusions}

In conclusion, the first part of the present work is a study of a new compound, tetraaqua bismaleato iron(II), containing maleate bridging ligand. The single-crystal $\mathrm{X}$-ray data show elongated tetragonal-bipyramidal coordination around iron(II). The water molecules and oxygen for maleato anions are connected through hydrogen bonds into 3D supramolecular frameworks. Thermal analysis confirmed the number of water molecules as well as the nature of connections in the network of these molecules. These results are in perfect agreement with the structural study.

In the second part, the study has proved that the synthesized compound showed high antibacterial and antifungal activities against Candida and the dermatophyte strains. The results confirm that we have succeeded to synthesize a new compound more effective than our previous compounds published by our laboratory. ${ }^{11,24}$

\section{Acknowledgements}

The authors are thankful to the Ministry of Higher Education and Scientific Research (Tunisia) for providing necessary facilities to carry out this research work.

\section{Supplementary Information}

Crystallographic data and full lists of bond lengths and angles have been deposited with the Cambridge Crystallographic Data Centre, CCDC No. 140005. Copies of this information may be obtained free of charge from The Director, CCDC, 12 Union Road, CAMBRIDGE CB2 1EZ, UK (fax: +44-1223336-033; e-mail: deposit@ccdc.cam.ac.uk or Error! Hyperlink reference not valid. Additional two figures are available in Supplementary Information at www.ias. ac.in/chemsci.

\section{References}

1. Maspoch D, Ruiz-Molina D and Veciana J 2007 Chem. Soc. Rev. 36770

2. Sato O, Tao J and Zhang Y Z 2007 Angew. Chem. Int. Ed. 462152
3. Kubota Y, Takata M, Kobayashi T and Kitagawa S 2007 Coord. Chem. Rev. 2512510

4. Smith C B, Barbour L J, Makha M, Raston L C and Sobolev A N 2006 Chem. Commun. 950

5. Zheng J L and Lin S K 2007 Acta Cryst. E63 m1607

6. Liu Y 2005 Acta Cryst. E61 m669

7. Spellberg B, Powers J H, Brass E P, Miller L G and Edwards J E 2004 Clin. Infect. Dis. 381279

8. Waterman H, Tillen D and Dickson R 2001 Health Technol. Assess. 51

9. Earnshaw A 1968 In Introduction to Magnetochemistry (London: Academic Press)

10. Collins M D, Facklam R R, Farrow J A E and Williamson R 1989 FEMS Microbiol. Lett. 57283

11. Essghaier B, Naouar A, Abdelhak J, Zid M F and Sadfi-Zouaoui N 2014 Microbiol. Res. 169504

12. Zhu J, Luther P W, Leng Q and Mixson A J 2006 Antimicrob. Agents Chemother. 502797

13. Jorgensen J H and Turnidge J D 2007 Am. Soc. Microbiol. 1152

14. Graciela M, Vignolo M, De Kairuz N, Aida A P, De Ruiz H and Oilver G 1995 J. Appl. Bacteriol. 785

15. Ryazanova L P, Stepnaya O A, Suzina N E and Kulaev I S 2005 Process Biochem. 40557

16. Kanters J A, Kroon J, Peerdeman A F and Schoone J C 1967 Tetraheron 234027

17. Nakamoto K 2009 In Infrared and Raman Spectra of Inorganic and Coordination Compounds Part B: Applications in Coordination, Organometallic, and Bioinorganic Chemistry 6th ed. (Hoboken, New Jersey: John Wiley)

18. Lever A B P 1984 In Inorganic Electronic Spectroscopy $2^{\text {nd }}$ ed. (Amsterdam: Elsevier) p. 212

19. Sabo T J, Grguric S R, Minic D M and Trifunovic S R 1998 J. Coord. Chem. 4447

20. Palamarciuc O V, Bourosh $\mathrm{P}$ N, Revenco M D, Lipkowski J, Simonov Y A and Clérac R 2010 Inorg. Chim. Acta 3632561

21. O’Connor C J 1986 Prog. Inorg. Chem. 29203

22. Abd El-Salam N M, Mostafa M S, Ahmed G A and Alothman O Y 2013 J. Chem. 20131

23. Zani F P, Mazzal P, Benvenutiz S, Severi F, Malmusiz L, Vampa G and Antolin L 1995 Eur. J. Med. Chem. 30 729

24. Abdelhak J, Essghaier B, Toukebri N, Naouar A, Rebib H, Zid M F and Sadfi-Zouaoui N 2014 J. Microbiol. Biotech. Food 4225

25. Sun J, Lv P C, Yin Y, Yuan R J, Ma J and Zhu H L 2013 PLoS One 8 e69751

26. Thanh-Dao T, Thi-Thao-Nhu N, Tuong-Ha D, ThiNgocPhuong H, Cat-Dong T and Khac-Minh T 2012 Molecules 176684 